\title{
SISTEM PENDIDIKAN NEGARA ABAD KE-21 BRUNEI DARUSSALAM DALAM MELESTARI KETAMADUNAN ISLAM NEGARA ZIKIR: CABARAN DAN HARAPAN
}

\author{
Masuriyati Yahya*, Che Zarrina Sa 'ari"
}

*Fakulti Usuluddin. Universiti Islam Sultan Sharif Ali. Simpang 347, Jalan Pasar Gadong. Bandar Seri Begawan. Brunei Darussalam.

${ }^{*}$ Akademi Pengajian Islam. Universiti Malaya. 50603. Kuala Lumpur. Malaysia.

Emel: "mysuri@yahoo.com."zarrina@um.edu.my.

\begin{abstract}
Khulasah
Sistem pendidikan memainkan peranan penting dalam menyumbang pembangunan dan melestari ketamadunan bangsa sesebuah negara dengan mengambil kira kepentingan aspek mental dan fizikal serta aspek rohani dan spiritual. Sistem Pendidikan Negara Abad ke-21 (SPN21) merupakan sistem pendidikan bersifat holistik. Dengan menggunakan kaedah perpustakaan dan berasaskan beberapa kajian lepas, artikel ini menghuraikan Sistem Pendidikan Negara Abad ke-21 (SPN21) dalam melestari ketamadunan Islam Negara Zikir dan mengemukakan pendidikan melalui teladan serta memiliki sifat murabbi dalam proses pengajaran dan pembelajaran dalam SPN21 yang memberi tumpuan dan fokus kepada pelajar (student centered learning) sebagai satu pendekatan. Dengan itu, SPN21 akan memberi memberi kesan dalam menangani permasalahan globalisasi yang antaranya memberi impak kepada pemikiran dan pembentukan akhlak individu pelajar Islam di Negara Brunei Darussalam.
\end{abstract}

Kata Kunci: Sistem pendidikan; SPN21; Negara Zikir; Globalisasi. 


\begin{abstract}
The education system plays an important role in contributing to the development and preserving the civilization of a country taking into account the importance of the mental, physical and spiritual, and spiritual aspects. National Education System of the 21st Century (SPN21) is a holistic education system. By using the library and a number of previous studies, this article describes the National Education System of the 21st Century (SPN21) preserving the Islamic civilization in the National Remembrance and submit education by example and has characteristic murabbi in the process of teaching and learning in SPN21 by focusing on student (student centered learning) as an approach. With it, SPN21 will give an impact in addressing the problems of globalization that such an impact on the thinking and moral development of the individual student Islam in Brunei Darussalam.
\end{abstract}

Keywords: Education system; SPN21; Islamic Civilization; globalization.

\title{
Pendahuluan
}

Asas kecemerlangan tamadun sesebuah bangsa adalah terletak pada kecemerlangan ilmu yang mampu melahirkan insan ideal berdasarkan sistem pendidikan holistik. Kejayaan dan keberkesanan sesuatu sistem pendidikan itu adalah bergantung kepada sejauh mana kejayaan dalam pembinaan ilmu yang dijana melalui proses pendidikan yang juga disokong oleh sistem bagi memastikan proses pendidikan tersebut berjalan sesuai dengan hala tuju dan matlamatnya.

Negara Brunei Darussalam sebagai sebuah negara yang sedang membangun, telah berusaha melaksanakan pelbagai bentuk perkembangan dan kemajuan. Selaras dengan perkembangan tersebut Sistem Pendidikan Negara Abad ke-21 (SPN21) telah pun diperkenalkan sebagai salah satu anjakan paradigma bagi membolehkan Negara 
Brunei sebagai sebuah Negara Melayu Islam Beraja dan juga Negara Zikir mencapai Wawasan 2035.

SPN21 mula dilaksanakan pada tahun 2008, tidak hanya menuntut perubahan yang besar dalam struktur dan sistem pendidikan, kurikulum dan penilaian dan juga pendidikan teknikal tetapi juga menuntut perubahan mentaliti, pemindahan dan penerapan nilai-nilai murni sebagai persiapan dalam menangani perkembangan arus globalisasi.

Cabaran globalisasi merupakan antara cabaran terbesar yang antaranya memberi impak kepada pemikiran dan pembentukan akhlak. SPN21 menerusi kurikulumnya, menjadi fokus utama makalah ini, merupakan antara komponen yang penting diberi perhatian terutama dalam usaha membentuk pelajar agar memiliki ketahanan mental, fizikal dan spiritual supaya pelajar tidak mudah terpengaruh dengan unsur-unsur negatif yang datangnya dari arus perkembangan globalisasi.

\section{Definisi}

Sistem bermaksud cara atau kaedah untuk melakukan sesuatu, aturan atau kumpulan beberapa bahagian (alat dan lain-lain) yang sama-sama bekerja untuk satu tujuan atau kumpulan pendapat (prinsip, teori dan lain-lain) yang teratur dan tersusun baik-baik (biasanya dijadikan pegangan), cara atau kaedah teratur untuk melakukan sesuatu. ${ }^{1}$

Tamadun yang bermaksud kebudayaan, kemajuan, dan peradaban ${ }^{2}$ iaitu merujuk kepada keadaan masyarakat manusia atau keadaan negara dan penduduknya yang telah mencapai taraf kemajuan kebendaan serta perkembangan pemikiran (sosial, budaya, politik) yang tinggi. ${ }^{3}$ Tamadun

${ }^{1}$ Kamus Dewan, ed. ke-4 (Kuala Lumpur: Dewan Bahasa dan Pustaka, 2007), 1507, entri "sistem."

2 Teuku Iskandar, Kamus Dewan (Kuala Lumpur: Dewan Bahasa dan Pustaka, 1970),1169.

${ }^{3}$ Kamus Dewan, 1583, entri "tamadun." 
juga berasal daripada perkataan Arab, dari kata akar ma da na dan kata nama atau kata terbitannya "madinah" yang bermaksud pembangunan di kota atau bandar. ${ }^{4}$

Gabungan perkataan Negara Zikir bermaksud negara yang mengingati Allah, negara menyebut Allah, negara yang tidak berpisah dengan Allah, negara yang tidak berenggang dengan Allah, negara yang basah keringnya dengan Allah, susah senangnya bersama-sama dengan Allah; harapannya, cita-citanya dan wawasannya sememangnya semata-mata demi memenangi redha Allah jua. $^{5}$

Negara Zikir juga bermaksud sebuah negara yang memiliki siasah, ekonomi, sosial dan pertahanannya yang berorientasi dan berpaksikan zikir. ${ }^{6}$ Negara Zikir juga merupakan imej sebuah negara yang menjunjung tinggi ajaran-ajaran Islam dan menjadikan ajaran Islam sebagai panduan dan amalan dalam seluruh aspek kehidupan agar nikmat, kerahmatan dan keberkatan akan sentiasa mengiringi dan melindungi negara. ${ }^{7}$ Firman Allah Subhanahu wa Taala:

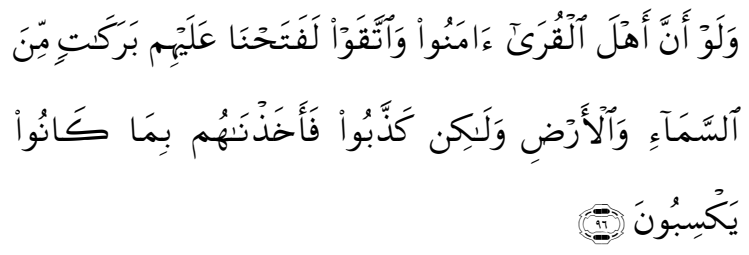

Terjemahan: Dan (Tuhan berfirman lagi):

Sekiranya penduduk negeri itu, beriman serta

${ }^{4}$ Ibn Manzur, Lisān al-`Arab (Beirut: Dār al-Ṣadir dan Dār Beirut, 1955), 56: 402.

${ }^{5}$ Adi Rumi, Negara Zikir (Brunei: Dewan Bahasa dan Pustaka, 2010), v-vi.

6 Abdul Aziz bin Juned, "Negara Zikir" (Kertas Perdana Majlis Ilmu 2008 di Pusat Persidangan Antarabangsa, Berakas, 28-29 Julai 2008), 6 .

7 Teks Perdana dalam Konvensyen Pendidikan Islam 2011 (Brunei: Pusat Persidangan Antarabangsa Berakas, 2011). 
bertaqwa, tentulah Kami akan membuka kepada mereka (pintu pengurniaan) yang melimpah-limpah berkatnya, dari langit dan bumi. Tetapi mereka mendustakan (Rasul Kami), lalu Kami timpakan mereka dengan azab seksa disebabkan apa yang mereka telah usahakan.

\section{Al-`Arāf (7): 96}

Ringkasnya, sistem pendidikan bersifat holistik amat diperlukan dalam proses membentuk masa depan bangsa cemerlang di samping mempertingkatkan taraf kehidupan sesuai dengan matlamat pendidikan dengan mengambilkira kepentingan kerohanian atau spiritual dan menjadikan Negara Zikir sebagai landasan utama dalam mencapai Wawasan 2035.

\section{Sejarah Sistem Pendidikan Dualisme di Brunei Sebelum Tahun 1950}

Aspek pendidikan merupakan aspek sosial yang sangat penting untuk diambil perhatian kerana kejayaan dan kemajuan sesebuah negara sangat bergantung kepada institusi pendidikan dalam melahirkan generasi cemerlang untuk meneruskan agenda pembangunan di masa hadapan. Kejayaan dalam bidang pendidikan juga sangat bergantung kepada sistem pendidikan yang melaksanakan proses pendidikan tersebut.

Sejarah pendidikan di Brunei pada zaman tradisi adalah bermula di Kampong Ayer yang merupakan pusat pemerintahan dan pentadbiran di samping sebagai pusat penyebaran agama Islam yang berkembang pesat. Pendidikan di Brunei telah pun melalui pelbagai bentuk sistem pendidikan yang mencorak pemikiran, sosio budaya dan sosio ekonomi masyarakat Brunei. Antaranya, sistem pendidikan balai yang menitikberatkan 
pembelajaran agama Islam yang diajarkan di balai-balai ${ }^{8}$ dan masjid-masjid di Kampong Ayer sebelum tahun 1906.

Kaedah mengajar dalam sistem pendidikan balai ialah dengan cara duduk "beliun" (bentuk bulatan). Bermaksud murid duduk dengan membuat bulatan seperti halaqah dan guru duduk di "siring" (di tepi). Semasa belajar, murid yang sudah pandai menulis akan diberikan kertas. Waktu belajar agama diadakan pada setiap hari di waktu pagi dan di sebelah petang selepas solat zohor, akan diteruskan dengan mengajar bacaan al-Quran. Tempoh masa belajar bagi setiap mata pelajaran tidak ditetapkan, bergantung sepenuhnya kepada guru. Oleh sebab itu, jika murid merasa "sengal" (penat atau letih), dia akan memohon diri untuk keluar dari majlis ilmu itu untuk berehat sementara waktu. ${ }^{9}$

Sistem pendidikan balai ini pada keseluruhannya banyak bergantung kepada kebolehan seseorang guru dalam memberikan kefahaman yang sejelas-jelasnya kepada muridnya. Ini disebabkan pada zaman dahulu tidak terdapat alat bantu mengajar. Pencapaian murid pula

8 Menurut masyarakat Melayu Brunei terdapat empat pengertian mengenai balai. Pertama, balai sebagai tempat menyimpan peralatan menangkap ikan seperti balat, tugu, jala, pukat dan lukah. Peranannya sama seperti stor. Kedua, balai sebagai tempat melakukan perusahaan atau pekerjaan seperti menjalin balat, bertukang perahu (memburis) dan perusahaan kayu bakau untuk kegunaan kayu api. Ketiga, balai sebagai tempat belajar seni silat atau seni mempertahankan diri. Keempat, balai sebagai tempat belajar agama, hadrah, sembahyang berjemaah dan bertadrus. Balai seperti ini pada lazimnya hanya dimiliki oleh tokoh-tokoh agama di kalangan pehin-pehin menteri agama, imam, bilal dan pengiranpengiran. Lihat nota kaki Awg Asbol bin Haji Mail, "Sejarah Perkembangan Pendidikan di Brunei 1950-1985" (disertasi MA, Jabatan Sejarah, Fakulti Sastera dan Sains Sosial, Universiti Malaya, 1995/96), 36.

${ }^{9}$ Pg Dr Haji Mohammad Pg Haji Abd Rahman, "Perkembangan Ilmu Islam di Brunei: Peralihan dari Sistem Balai ke Sistem Persekolahan Moden (1931-1956)" (makalah, Seminar Bahan Rujukan Islam Nusantara, Jabatan Mufti, 20-23 Ogos 2001), 4-5. 
adalah terletak kepada kemahiran menulis yang dimiliki dan mempunyai daya hafalan yang tinggi. ${ }^{10}$

Tenaga pengajar dalam sistem balai adalah terdiri daripada tokoh-tokoh ulama Brunei tempatan dan juga tokoh ulama yang datang dari luar negara. Antara kitabkitab yang digunapakai untuk mengajar dalam sistem balai ini adalah terdiri daripada kitab Tasawuf, Fiqh, Tauhid, Akhlak, Sorof, Fara'id, Tafsir, Hadith dan lain-lain lagi. ${ }^{11}$

Apabila kuasa British bertapak di Brunei, ianya tidak cuma merubah sistem politik, pentadbiran, ekonomi dan undang-undang, bahkan juga secara langsung mempengaruhi sistem pendidikan Brunei. Pihak British telah memperkenalkan sistem pendidikan sekular berbentuk formal kepada masyarakat Brunei. Ini menjadikan wujudnya sistem dualisme iaitu sistem pendidikan agama Islam dan sistem sekular. ${ }^{12}$

Pendidikan agama Islam merupakan sistem pendidikan yang mengajarkan aspek keagamaan seperti mengaji al-Quran, belajar hukum-hukum Islam, ibadat, sejarah Islam dan lain-lain lagi. Matlamat utama sistem pendidikan ini untuk membentuk umat manusia yang beriman kepada Allah agar kehidupan mereka berbahagia di dunia dan di akhirat. ${ }^{13}$

Sementara itu sistem pendidikan sekular dalam pembicaraan ini bermaksud sebagai sistem persekolahan yang mengajarkan mata pelajaran-mata pelajaran seperti matematik, sains, sejarah, geografi, perdagangan dan sebagainya di mana dari aspek pengajarannya tidak mengambil kira atau kurang mementingkan unsur-unsur keagamaan. Sistem pendidikan seumpama ini diterapkan di sekolah-sekolah Melayu, Cina dan Inggeris. ${ }^{14}$

${ }^{10}$ Ibid.

${ }^{11}$ Ibid., 5.

12 Awg Asbol "Sejarah Perkembangan Pendidikan di Brunei 19501985", 33.

${ }^{13}$ Ibid.

${ }^{14}$ Ibid., 34. 
Sekolah Rendah Melayu pertama telah pun ditubuhkan pada tahun 1914 dengan tujuan memberikan kemahiran asas membaca dan menulis dalam huruf rumi disebabkan ketiadaan pakar dalam bidang tersebut. Sekolah ini mula beroperasi di masjid kerana bangunan khas belum dibina. Pada ketika itu, masjid merupakan tempat yang paling sesuai untuk kegiatan pendidikan. Malah pendidikan di masjid akan menarik minat ibu bapa untuk membenarkan anak-anak mereka menyertai sistem pendidikan yang diperkenalkan di samping dapat memberikan keyakinan kepada ibu bapa bahawa sistem pendidikan yang baru ini memang tidak bertentangan dengan hukum agama. ${ }^{15}$

Pada tahun 1916, masyarakat Cina juga telah menubuhkan sekolah Cina yang bertempat di sebuah kedai di Pekan Brunei dengan tujuan supaya anak-anak masyarakat Cina mendapat pendidikan dengan lebih teratur. Buat permulaan sekolah ini mempunyai seramai 38 orang murid. Sekolah ini menggunakan bahasa Mandarin sebagai bahasa pengantar. ${ }^{16}$

Di samping pendidikan agama, Melayu dan Cina, anak-anak Brunei juga memasuki sekolah-sekolah beraliran Inggeris. Sebelum ada sekolah Inggeris Kerajaan, mereka yang memerlukan pendidikan Inggeris terpaksa memasuki sekolah misi atau pergi ke luar negeri. Mereka yang mengikuti sekolah Inggeris di seberang laut di hantar ke Labuan oleh kerajaan. Penghantaran ini telah dilakukan sejak tahun 1919 dengan dua orang murid setahun. Ianya berterusan sehingga tahun $1941 .^{17}$

Idea untuk menubuhkan sekolah Inggeris kerajaan ini telah wujud dalam tahun 1920-an lagi. Namun idea ini tidak dapat dilaksanakan kerana ibu bapa tidak bersedia menghantar anak-anak mereka ke sekolah Inggeris kerana

\footnotetext{
${ }^{15}$ Ibid., 41-42.

${ }^{16}$ Ibid., 43.

${ }^{17}$ Ibid.
} 
bimbang ajaran agama Kristian akan mempengaruhi anakanak mereka memandangkan sekolah Inggeris ditadbir oleh orang-orang Inggeris atau lain-lain bangsa yang keseluruhannya beragama Kristian. ${ }^{18}$

Pada tahun 1931, mata pelajaran agama mula diajarkan secara formal sebagai satu mata pelajaran di Sekolah Melayu, Jalan Pemanca, Pekan Brunei. Ini dilakukan atas dorongan tiga orang pembesar Brunei yang terdiri dari Pengiran Bendahara Abdul Rahman, Pengiran Pemanca Haji Mohd Yassin dan Pengiran Shahbandar Hashim. Kemungkinan mereka ini menyedari bahawa perlunya pendidikan agama itu dimasukkan ke dalam persekolahan Melayu agar ia dapat diajarkan dengan lebih berkesan. ${ }^{19}$

Pada tahun 1941, sekolah agama aliran Arab diwujudkan tetapi terhenti akibat tercetusnya Perang Dunia Kedua. Walau bagaimanapun, pengukuran pertumbuhan persekolahan di Brunei semakin menggalakkan dengan wujudnya sekolah misi dan sekolah Inggeris swasta di Daerah Belait berikutan berkembangnya sektor industri minyak di daerah tersebut. $^{20}$

Sebelum tahun 1950, pertumbuhan persekolahan di bawah urus tadbir kerajaan agak perlahan kerana tahap pelajaran yang diberikan adalah dalam peringkat rendah sahaja. Hal ini berlaku disebabkan tumpuan utama diberikan kepada perkembangan dan pembangunan aspek ekonomi dan lain-lain aspek. Pada masa yang sama tahap kesedaran majoriti masyarakat Brunei tentang kepentingan pendidikan formal kepada kanak-kanak juga berada di tahap yang rendah.

Demikianlah sejarah sistem pendidikan di Brunei dalam bentuk dualisme di mana pendidikan formal di

\footnotetext{
${ }^{18}$ Ibid., 44-45.

${ }^{19}$ Ibid., 38.

${ }^{20}$ Ibid., 46-48.
} 
Brunei dari tahun 1914 hingga 1930 dikuasai oleh pendidikan sekular yang terbahagi kepada dua aliran iaitu Sekolah Melayu dan Sekolah Cina. Sementara pendidikan Islam diterima secara formal pada tahun 1931 di samping tidak dinafikan wujudnya sekolah agama aliran Arab pada tahun 1941.

Kini negara Brunei Darussalam merupakan sebuah negara yang merdeka lagi berdaulat, berdasarkan falsafah Melayu Islam Beraja dan juga Negara Zikir maka kerajaan Brunei telah mengemaskinikan sistem pendidikan kebangsaan yang dikenali dengan Sistem Pendidikan Abad ke-21 atau SPN21.

\section{Sistem Pendidikan Negara Abad ke-21 (SPN21)}

Sistem Pendidikan Negara abad ke-21 merupakan sistem pendidikan di negara Brunei Darussalam yang telah pun diluluskan oleh Kementerian Pendidikan Negara Brunei Darussalam. Sistem ini diperkenalkan sebagai salah satu anjakan paradigma bagi membolehkan negara Brunei sebagai sebuah 'Negara Melayu Islam Beraja' menerusi konsep Negara Zikir untuk mencapai Wawasan 2035 yang memfokuskan tiga perkara utama; pertama rakyat yang berpendidikan, berkemahiran tinggi dan berjaya; kedua, kehidupan rakyat yang berkualiti; dan ketiga ekonomi yang dinamik dan berdaya tahan.

Dasar SPN21 adalah merujuk kepada beberapa sistem yang pernah diterap dan digunapakai sebelum ini seperti Sistem Dwibahasa 84, yang masih mengutamakan bahasa Inggeris dan bahasa Melayu cuma dalam SPN21 tumpuan dan fokus utama diberikan kepada pelajar iaitu memusatkan pembelajaran dan pengajaran kepada pelajarpelajar student centered learning sebagai satu pendekatan. $^{21}$

${ }^{21}$ Eddy Iswandy Haji Ismail, "Integrasikan Pendidikan Teknik dan Vokasional," Pelita Brunei, 18 March 2013. 
Pendekatan memusatkan pembelajaran dan pengajaran kepada pelajar-pelajar dalam SPN21 adalah berbeza dengan sistem lama yang menggunakan pendekatan examination oriented. Pendekatan examinataion oriented memberi impak kepada guru-guru untuk mengulang kaji menggunakan kertas soalan peperiksaan yang lepas sahaja berbanding memahami konsep-konsep tertentu yang lebih penting untuk diperjelaskan dan difahamkan kepada pelajar. ${ }^{22}$

Tujuan SPN21 adalah untuk:

i. Memenuhi keperluan-keperluan dan cabaran-cabaran perkembangan pembangunan ekonomi dan sosial abad ke-21.

ii. Merealisasikan visi dan misi Kementerian Pendidikan

iaitu: Visi: "Pendidikan Berkualiti ke arah Negara yang Membangun, Aman dan Sejahtera". Misi: "Untuk Memberikan Pendidikan yang Holistik (sempurna) bagi Mencapai Potensi yang Penuh Bagi Semua".

iii. Menyediakan kemahiran-kemahiran abad ke-21.

iv. Memenuhi tema-tema strategik berdasarkan Pelan Strategik Kementerian Pendidikan (2007-2011).

v. Meningkatkan kadar jumlah penuntut di peringkat pendidikan tinggi dari kadar 14 peratus yang sedia ada masa kini ke tahap 30 peratus dalam jangka waktu lima tahun akan datang.

vi. Mencapai matlamat untuk membolehkan sekurangkurangnya 50 peratus jumlah penuntut lepasan sekolah menengah termasuk lepasan sekolah vokasional dapat meneruskan pelajaran di peringkat tertinggi.

vii. Terus berusaha ke arah meningkatkan lagi kualiti kehidupan di negara ini melalui penyediaan dan

${ }^{22}$ Norliah Md Zain, "SPN21 Berdasarkan Student Centred Learning Bukan Examination Oriented," Pelita Brunei, 18 March 2013. 
pembaharuan sistem pendidikan yang lebih berupaya dan berdaya saing untuk meningkatkan kecekapan rakyat dan penduduk Brunei.

viii. Mencapai wawasan Brunei 2035. ${ }^{23}$

\section{Perlaksanaan SPN21}

SPN21 dilaksanakan untuk meningkatkan kualiti pengajaran dan pembelajaran dengan menyediakan kurikulum dan penilaian serta struktur yang fleksibel dalam memberikan pelbagai laluan ke peringkat pengajian tinggi dan juga menyediakan prasarana yang mencukupi bagi mengadakan latihan-latihan kemahiran.

SPN21 mula dilaksanakan pada tahun 2008. Perlaksanaannya dilakukan secara berperingkat di mana peringkat interim atau peralihan bermula pada peringkat menengah tahun 2008 yang melibatkan kumpulan pelajar yang telah lulus dalam Peperiksaan Sekolah Rendah (PSR) pada tahun 2007. Perlaksanaan bagi peringkat rendah pula bermula pada tahun 2009 iaitu bagi pelajar Tahun 1 dan Tahun 4 dan perlaksanaan SPN21 sepenuhnya di peringkat rendah pada tahun 2011.

Untuk memastikan matlamat SPN21 tercapai, beberapa strategi berupa rancangan teratur yang mengambil kira pelbagai faktor telah pun difikirkan dan Kementerian Pendidikan telah menggariskan lapan haluan dasar untuk mencapai strategi SPN21 iaitu:

i. Pelaburan dalam pendidikan awal kanak-kanak.

ii. Penggunaan amalan terbaik antarabangsa dalam pengajaran dan pembelajaran.

iii. Mengadakan pendidikan bertaraf tinggi di peringkat menengah dan pengajian tinggi termasuk sekolahsekolah vokasional ke arah melahirkan tenaga pakar,

23 Mohammad Huzaiman bin Haji Kassim, “Adakah Spn21 Itu Mendukung Visi Dan Misi Jabatan Pengajian Islam?” (makalah, Fakulti Usuluddin, Kolej Universiti Perguruan Ugama Seri Begawan, 2009). 
ahli profesional dan juru teknik berkemahiran yang diperlukan dalam perniagaan dan industry.

iv. Memperkukuh kompetensi dalam teknologi info komunikasi (ICT) bagi penuntut, guru dan pentadbir pendidikan termasuk integrasi ICT ke dalam kurikulum sekolah.

v. Membentuk program yang menggalakkan pembelajaran sepanjang hayat dan meningkatkan akses kepada pendidikan tinggi.

vi. Menggalakkan penyelidikan, perkembangan dan inovasi di institusi yang dibiayai oleh perkongsian sektor awam swasta dan antarabangsa.

vii. Menggunakan kaedah pengajaran 'cost-effective' melalui penggunaan teknologi.

viii. Memperbaiki pengurusan semua institusi pendidikan. ${ }^{24}$

\section{Perubahan dalam SPN21}

Perlaksanaan SPN21 melibatkan perubahan besar pada struktur dan sistem pendidikan, kurikulum dan penilaian serta pendidikan teknikal. Perlaksanaan SPN21 ini dijangka selesai pada tahun 2015. Perubahan ini memberi penekanan terhadap pendidikan berkualiti melalui kurikulum seimbang, relevan, dinamik dan berbeza selaras dengan Wawasan 2035.

\subsection{Struktur dan Sistem Pendidikan}

Struktur sistem pendidikan SPN21 telah disusun atur dan diselaraskan sesuai untuk semua peringkat dan golongan pelajar dengan menyediakan Program Pendidikan Khusus bagi pelajar berbakat atau memiliki kecerdasan yang tinggi dan juga Program Pendidikan Berkeperluan Khas bagi pelajar kurang penglihatan, mempunyai tantangan mental dan fizikal serta bagi pelajar yang mempunyai kesukaran pembelajaran yang spesifik.

${ }^{24}$ Sahari Akim, "Keluaran khas sempena Sambutan Hari Kebangsaan ke-24”, Pelita Brunei, 20 Feb 2008. 
Menerusi SPN21, pelajar diberi peluang untuk memilih sama ada ingin mengikuti Program Pendidikan Menengah bagi tempoh selama empat tahun (Tahun 7 hingga Tahun 10) atau bagi tempoh lima tahun (Tahun 7 hingga Tahun 11) sebelum menduduki peperiksaan BC GCE Peringkat 'O' atau kelulusan yang sebanding. Bagaimanapun semua pelajar akan mengikuti kurikulum yang sama selama dua tahun (Tahun 7 dan Tahun 8).

Selepas Tahun 8, pelajar-pelajar akan disalurkan untuk mengikuti program berikut:

a. Program Pendidikan Menengah General (Tahun 9 hingga 10 atau Tahun 9 hingga 11)

b. Program Pendidikan Menengah Applied (Tahun 9 hingga 11$)^{25}$

25 Sistem Pendidikan Negara Abad Ke-21 SPN21, Kementerian Pendidikan Negara Brunei Darussalam, 2008. 
Masuriyati \& Che Zarrina, "Sistem Pendidikan Negara Abad ke-21," Afkār 16

(Januari-Jun 2015): 61-92

\section{Rajah 1. Struktur Sistem Pendidikan Negara Abad Ke $21\left(\right.$ SPN21) ${ }^{26}$}

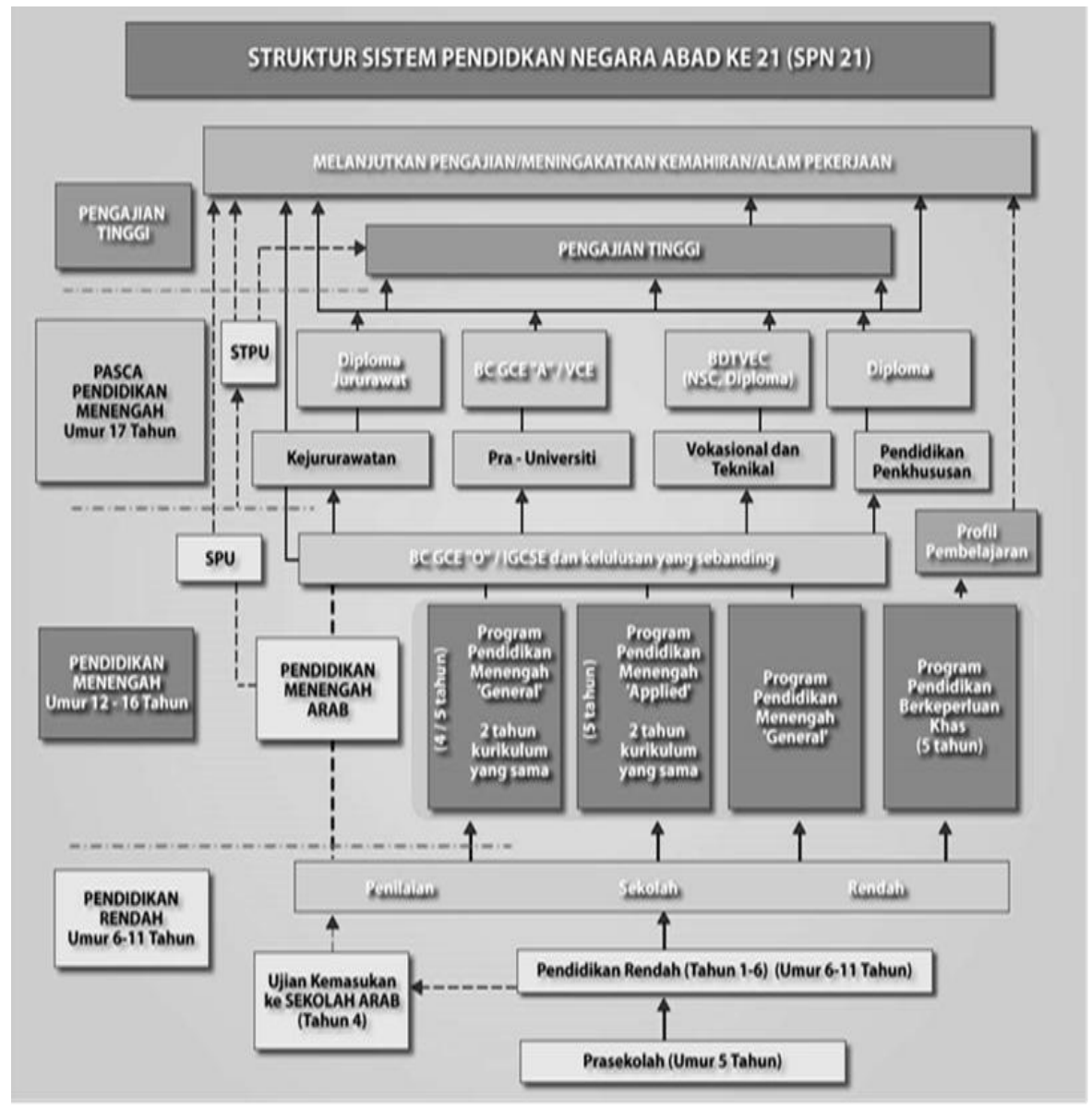

${ }^{26}$ Sistem Pendidikan Negara Abad ke-21 SPN21, 2008. 
Masuriyati \& Che Zarrina, "Sistem Pendidikan Negara Abad ke-21," Afkār 16 (Januari-Jun 2015): 61-92

Rajah 2. Perbezaan sistem asal dengan SPN21 ${ }^{27}$

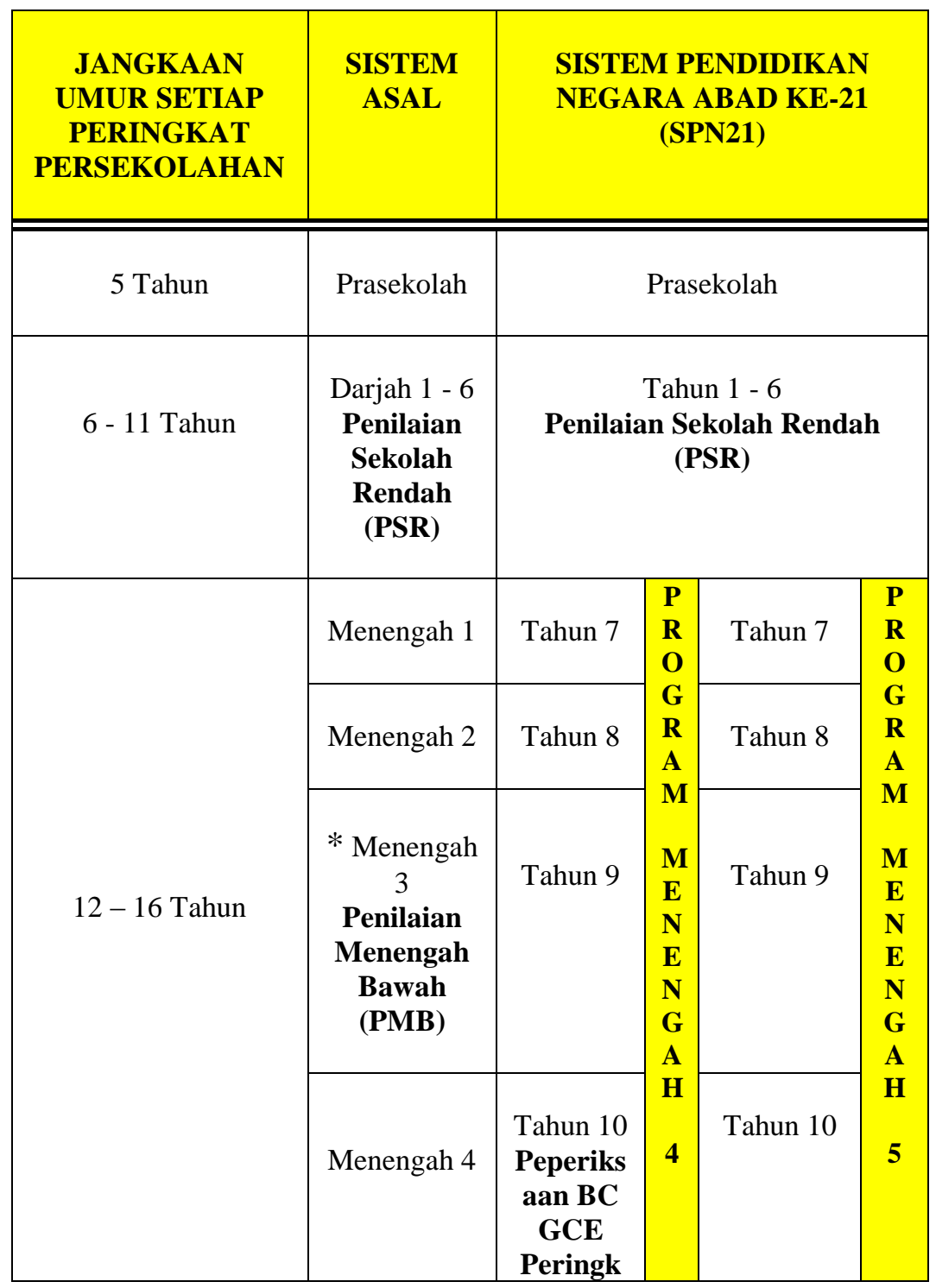

${ }^{27}$ Sistem Pendidikan Negara Abad Ke-21 SPN21, 2008 


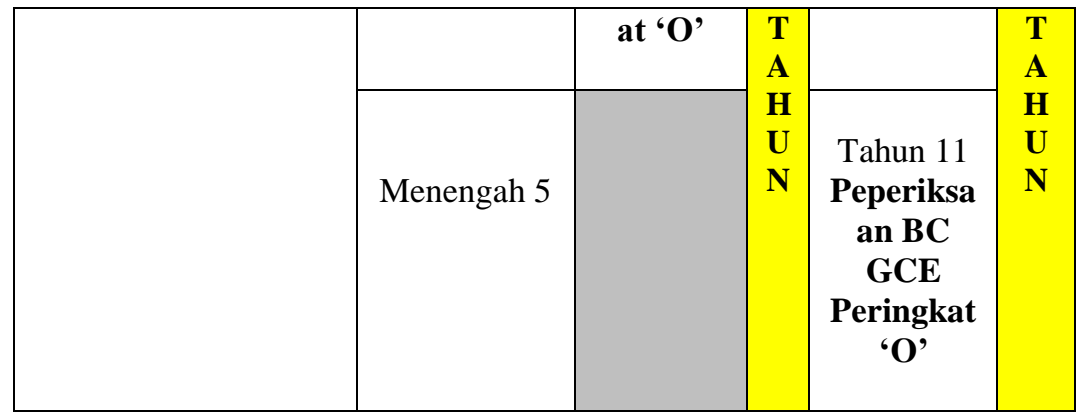

Rajah 2 di atas, menunjukkan terdapat perubahan dari segi penggunaan 'darjah' dan 'menengah' iaitu diubah menjadi 'tahun' seperti Tahun 1-6 bagi menggantikan darjah 1-6 dan Tahun 7-11 bagi menggantikan Menengah 1-5. Perubahan ini adalah selaras dengan tempoh dan jangka masa persekolahan iaitu sekurang-kurangnya dua belas tahun.

Begitu juga terdapat perbezaan dari segi tempoh dan jangka masa persekolahan selepas Menengah 3. Dalam sistem lama, berdasarkan keputusan Menengah 3, pelajar meneruskan persekolahan ke Menengah 4 dan Menengah 5.

Berbanding dengan sistem baru SPN21, berdasarkan keputusan Menengah 3, pelajar akan ditawarkan sama ada mengikuti Menengah 4 selama satu tahun sahaja, iaitu menduduki Tahun 10 (nama dikenali dalam SPN21) dan mengikuti peperiksaan BC GCE Peringkat 'O' pada tahun yang sama atau mengikuti Menengah 4 selama dua tahun iaitu menduduki Tahun 10 dan Tahun 11 (nama dikenali dalam SPN21), di mana pelajar akan mengikuti peperiksaan BC GCE Peringkat 'O' dalam Tahun 11.

Dengan kata lain, SPN21 memberi fokus dalam membantu pelajar untuk melihat ke mana hala tuju pelajar selepas Menengah 3. Malah penetapan matlamat hala tuju boleh dipersiapkan dari Tahun 7 lagi. Justeru, SPN21 bukan hanya sistem semata tetapi telah menyerapkan 
bersama satu pemikiran 'siap siaga' untuk masa depan pelajar yang diberikan dalam bentuk alternatif. Oleh itu, pelajar, ibu bapa dan tenaga pengajar perlu diperjelas dan diberi kefahaman tentang niat murni pihak Kementerian Pendidikan sebagai sebuah kementerian yang menitik beratkan pendidikan dan masa depan anak bangsa sekali gus memenuhi Wawasan 2035.

Dengan wujudnya persefahaman antara pelajar, ibu bapa dan tenaga pengajar akan memudahkan wujudnya kerjasama antara mereka dengan pihak kementerian dan ini sangat membantu untuk mencapai matlamat Kementerian Pendidikan berdasarkan pelan strategi yang disediakan.

\subsection{Kurikulum dan Penilaian}

\subsubsection{Kurikulum}

Kurikulum SPN21 memfokuskan bidang pembelajaran yang luas bagi membolehkan pelajar mendapat pengetahuan dan kefahaman, kemahiran asas serta sikap dan nilai untuk memastikan perkembangan menyeluruh yang bersesuaian dengan konteks abad ke-21. Kebawah Duli Yang Maha Mulia Paduka Seri Baginda Sultan dan Yang Di Pertuan Negara Brunei Darussalam telah memartabatkan pendidikan agama Islam dalam SPN21 dengan meletakkannya sebagai core subject atau mata pelajaran teras yang wajib diambil oleh setiap pelajar sebagaimana juga mata pelajaran Bahasa Melayu, Inggeris, Matematik, Sains dan MIB. ${ }^{28}$

Kurikulum SPN21 adalah merangkumi lapan bidang pembelajaran yang ditempatkan sebagai subjek teras iaitu Bahasa, Matematik, Sains, Sains Sosial dan Kemanusian, Kesenian dan Kebudayaan, Teknologi, Pendidikan Agama

28 Teks Perdana dalam Konvensyen Pendidikan Islam 2011 (Brunei: Pusat Persidangan Antarabangsa Berakas, 2011). 
Islam dan Melayu Islam Beraja serta Pendidikan Jasmani dan Kesihatan. ${ }^{29}$

Selain itu, kurikulum SPN21 juga menekankan beberapa kemahiran asas yang relevan untuk mencapai Wawasan 2035 antaranya; kemahiran berkomunikasi, kemahiran Sains dan ICT, kemahiran berfikir dan kreativiti, kemahiran bekerja dan belajar, kemahiran pengurusan diri dan berdaya saing, kemahiran berinteraksi, kemahiran fizikal, kemahiran estetika dan lain-lain kemahiran abad-21. ${ }^{30}$

Di samping kemahiran tersebut, nilai-nilai teras dan juga sikap perlu diterapkan seperti keyakinan dan harga diri, menghargai dan memahami perasaan orang lain, berdikari, toleransi dan hormat menghormati, penyayang, prihatin dan sensitif, integriti, cintakan negara, bertakwa, berdaya saing serta siap siaga. ${ }^{31}$

\subsubsection{Penilaian Kemajuan Pelajar (PKP)}

Sistem penilaian dalam SPN21 juga turut mengalami perubahan yang besar, dikenali dengan Penilaian Kemajuan Pelajar (PKP) atau Student Progress Assessment (SPA). Penilaian ini digunakan bagi menggantikan Penilaian Menengah Bawah (PMB) yang telah pun tamat pada tahun 2010. Penilaian Kemajuan Pelajar (PKP) atau Student Progress Assessment (SPA) mengandungi dua komponen iaitu:

i. Penilaian Kendalian Sekolah / School-Based Assessment (SBA) dilaksanakan sepanjang pelajar berada dalam Tahun 7 dan Tahun 8 .

ii. Peperiksaan Kemajuan Pelajar / Student Progress Examination (SPE) dilaksanakan pada akhir Tahun 8.

29 Sistem Pendidikan Negara Abad Ke-21 SPN21, Kementerian Pendidikan Negara Brunei Darussalam, 2008.

${ }^{30}$ Ibid.

${ }^{31}$ Ibid. 
Tujuan perlaksanaan Penilaian Kemajuan Pelajar (PKP) atau Student Progress Assessment (SPA) adalah untuk menentukan pemilihan pelajar bagi mengikuti Program Pendidikan Menengah General (4 atau 5 tahun) atau Program Pendidikan Menengah Applied (5 tahun).

Sementara itu, Penilaian Sekolah Rendah (PSR) masih dijalankan seperti biasa yang mana akan diduduki oleh pelajar Tahun 6. Pelajar yang gagal dalam PSR akan dikehendaki menduduki peperiksaan ulangan (resit) ${ }^{32}$

\subsection{Pendidikan Teknikal dan Vokasional}

Langkah transformasi landskap pendidikan teknik dan vokasional adalah mengambil kira kedudukan masa hadapan yang berjangka panjang dan ke arah pembangunan yang berdaya tahan (sustainable). Perlaksanaan transformasi ini juga mengambil kira pelbagai aspek termasuklah infrastruktur, dasar, kelulusan yang ditawarkan, malah kepada merubah persepsi masyarakat khususnya para ibu bapa mengenai pendidikan teknik dan vokasional. Transformasi ini meliputi menaik taraf institusi-institusi teknik dan vokasional menjadikannya sebagai pusat-pusat kecemerlangan. Di samping itu, peningkatan kapasiti tenaga pengajar teknik dan vokasional juga dilaksanakan melalui latihan perkembangan dan kongsi sama di mana tenaga-tenaga pengajar akan mula didedahkan kepada pengalaman bekerja di sektor perindustrian. ${ }^{33}$

Kini, hala tuju transformasi Pendidikan Teknik menjadi semakin kukuh dengan tertubuhnya Institut Pendidikan Teknikal Brunei di mana proses transformasi dilakukan dengan menyusun semula sistem pendidikan teknik sejajar dengan keperluan industri dan permintaan pekerjaan. Penubuhan institut tersebut juga untuk mengelakkan ketidaksepadanan kelayakan dengan

\footnotetext{
${ }^{32}$ Ibid.

${ }^{33}$ Khartini Hamir, "Peruntukan Bagi Berbagai Keperluan Pendidikan," Pelita Brunei, 16 March 2013.
} 
pekerjaan di samping untuk menampung permintaan jumlah lepasan sekolah menengah yang semakin meningkat setiap tahun. ${ }^{34}$

\section{SPN21 dan Cabaran Globalisasi}

Perkembangan teknologi maklumat dan penggunaan komputer yang cepat dan mudah merupakan nadi penting dalam sistem sosial masyarakat hari ini bahkan mendominasi ruang lingkup kehidupan seharian di samping membantu dalam menjimatkan banyak masa dan tenaga. Tidak dinafikan juga, perkembangan tersebut menjadi wadah untuk menyebarkan maklumat yang belum pasti lagi kesahihannya. Sebahagian daripada maklumat tersebut ada yang benar dan tepat dan begitulah sebaliknya. Penggunaan laman web, media sosial; facebook, twitter, blog dan sebagainya perlu dimanfaatkan dengan cara berhemah dan maklumat yang diperolehi perlu disaring dengan adil dan saksama.

Berdasarkan statistik yang dikeluarkan oleh laman web www.internetworldstats.com sehingga Jun 2012 mencatatkan seramai 318,900 pengguna daripada jumlah penduduk di Brunei 408,786 (tahun 2012) adalah pengguna internet dan sehingga Disember 2012 mencatatkan seramai 254,760 adalah pengguna facebook iaitu $78 \%$ menembusi per statik Kesatuan Telekomunikasi Antarabangsa [penetration per International Telecommunication Union (ITU)]. ${ }^{35}$

Melihat kepada jumlah pengguna internet dan facebook tersebut menunjukkan satu jumlah yang besar bagi negara Brunei yang perlu diambil perhatian meskipun kemungkinan belum ada kajian lengkap dan terperinci mengenainya dilakukan di dalam negara tersebut.

\footnotetext{
${ }^{34}$ Haji Ali bin Haji Apong, "Teks Ucapan" dalam Majlis Konvokesyen Kebangsaan Institut-Institut Pendidikan Teknik dan Vokasional ke21 (Brunei: Universiti Brunei Darussalam, 2014).

35 Laman sesawang International Telecommunication Union, http://www.internetworldstats.com.
} 
Di samping itu, ledakan maklumat hasil daripada perkembangan media massa hari ini juga turut menjadi cabaran yang mempengaruhi pola fikir dan gaya kehidupan dunia global. Tidak dinafikan, sebahagian besar maklumat tersebut memberi kesan negatif terhadap pembentukan akhlak dan juga nilai-nilai moral individu, keluarga dan masyarakat keseluruhannya. Kajian menyebutkan bahawa salah satu punca berlakunya keruntuhan akhlak remaja masa kini adalah hasil daripada paparan bahan dan rancangan media massa. Hasil penelitian para pengkaji juga menunjukkan bahawa paparan media elektronik dan media cetak boleh mempengaruhi tingkah laku golongan remaja yang juga dikategorikan sebagai pelajar. ${ }^{36}$

Kajian lain pula menyebutkan bahawa golongan remaja dan muda-mudi hari ini menghidap penyakit ketagihan internet. Antara simptom atau tanda-tanda ketagihan internet; banyak masa dihabiskan dengan aktiviti online internet, berkurangnya aktiviti fizikal dan kehidupan sosial, lalai daripada tanggungjawab rumah, kerja dan tugasan pelajar, membelanjakan wang yang banyak untuk perkakasan komputer dan aktiviti internet dan perasaan keinginan yang tinggi untuk berada "online" ketika jauh daripadanya. ${ }^{37}$

Kesan negatif hasil daripada perkembangan globalisasi tersebut menuntut pihak pelaksana yang terlibat dalam pendidikan mengambil inisiatif untuk memperkasakan sistem pendidikan dengan menyediakan kurikulum seimbang memenuhi keperluan fizikal, mental dan spiritual sebagai asas penting untuk membina benteng kukuh dan untuk mewujudkan sistem kawalan dalaman

${ }^{36}$ Malaysia, P. I. P., Pengaruh Media Massa Terhadap Penampilan Akhlak, The Online Journal of Islamic Education 1, (Januari 2013).

${ }^{37}$ Asar Abdul Karim, "Realiti Media Massa Masa Kini”, dalam Modal Insan: Konsep, Aplikasi dan Isu-Isu Kontemporari dalam Cabaran Pemerkasaan Tamadun Insan (Pahang: Universiti Malaysia Pahang, 2007), 257-258. 
yang efektif serta mempunyai tingkat kewaspadaan yang tinggi agar generasi remaja atau pelajar tersebut terselamat daripada arus perkembangan yang boleh merosakkan pemikiran dan akhlak, nilai-nilai moral dan juga jati diri.

Dengan kata lain, perkembangan pendidikan negara SPN21 tidak hanya menitikberatkan bidang akademik tetapi juga memberi penekanan dan mengambil kepentingan terhadap kesempurnaan pembangunan insan dengan menerapkan kurikulum holistik dan dinamik sebagai salah satu pendekatan terbaik dalam mengatasi masalah sosial global masa kini.

Kepentingan dan keperluan kepada penerapan kurikulum holistik dan dinamik boleh dirujuk kepada falsafah Pendidikan Kebangsaan Negara Brunei Darussalam:

Pendidikan kebangsaan negara Brunei Darussalam adalah usaha yang berterusan bersumber ilmu naqli dan ‘aqli ke arah memperkembangkan potensi individu serta menyeluruh bagi melahirkan insan berilmu, beriman, beramal, berkepandaian, bertaqwa, amanah, bertanggungjawab serta berakhlak mulia. Segala usaha ini akan mewujudkan masyarakat berilmu dan berwawasan yang akan menyumbang kepada keamanan dan kemakmuran keluarga, masyarakat, negara dan sejagat serta menimbulkan suatu identiti kebangsaan berdasarkan falsafah Negara Melayu Islam Beraja menurut Ahlissunnah Waljamaah sebagai tapak pertumbuhan dan pengukuhan ketaatan kepada agama, raja dan negara Brunei Darussalam. ${ }^{38}$

${ }^{38}$ Pg Mohammad Pg Abd Rahman, Belia dan Pendidikan Islam di Brunei Darussalam (Brunei: Pusat Da'wah Islamiah, 2011), 90-91. 
Intisari daripada falsafah pendidikan kebangsaan tersebut menjelaskan bahawa sistem pendidikan di Brunei merupakan usaha berterusan dengan mengambil kira keperluan duniawi dan ukhrawi secara seimbang dan sederhana. Persoalan bagaimana caranya sistem tersebut dilaksanakan adalah tertakluk kepada kebijaksanaan pihak-pihak berkenaan dengan mendapat restu daripada pemimpin negara. ${ }^{39}$

Falsafah pendidikan tersebut menyebutkan bahawa naqli dan 'aqli adalah sumber ke arah memperkembangkan potensi individu. Menurut al-Ghazāli ilmu naqliyyah diistilahkan sebagai ilmu fardhu ain manakala ilmu ‘aqliyyah pula diistilahkan sebagai ilmu fardhu kifayah. Fardhu ain ialah ilmu yang wajib dipelajari oleh setiap orang secara individu yang terlibat sama ada lelaki atau perempuan seperti ilmu berkenaan tentang rukun iman, ibadah, akhlak dan halal haram. Manakala fardhu kifayah pula ialah ilmu yang mesti dipelajari secara kolektif atau individu yang berkaitan dengan keperluan kehidupan manusia di dunia ini contohnya ilmu perubatan, ekonomi, pendidikan, kejuruteraan, ketenteraan dan sebagainya. ${ }^{40}$

Ringkasnya, ilmu naqli adalah ilmu ketuhanan, keimanan dan ketauhidan. Ilmu ini merupakan ilmu wahyu yang bersifat transendental iaitu datangnya dari Allah. Ilmu ‘aqli pula ilmu yang dicari dan diperoleh di kalangan manusia sendiri. Ilmu naqli dikenali sebagai "revealed knowledge" dan ilmu 'aqli dikenali sebagai "acquired knowledge". Ilmu naqli adalah ilmu hamba mengenali Pencipta. Ilmu 'aqli pula ilmu hubungan manusia sesama manusia sebagai khalifah di muka bumi. ${ }^{41}$

\footnotetext{
${ }^{39}$ Ibid.

40 Abu Hamid al-Ghazzāli, Ihyā 'Ulūm al-Dīn, terj. H. Moh Zuhri (Semarang: CV. Asy Syifa, 2011), 53.

${ }^{41}$ Ibid.
} 
Dengan kata lain, sistem pendidikan bersifat holistik dan dinamik mengambil kira kepentingan ilmu naqli dan 'aqli di mana keduanya harus berjalan secara bersepadu dan seiring dan juga mengambil kira kepentingan unsur fizikal, mental dan spiritual sebagai asas daya tahan dalam menghadapi sebarang cabaran yang pelbagai sesuai mengikut peredaran zaman serta keperluan masa dan tempat.

\section{SPN21 dan Cabaran Pembentukan Akhlak}

Islam sangat menitikberatkan pembentukan akhlak kerana akhlak mampu membentuk jiwa agar tunduk dan patuh kepada perintah Allah di samping mampu membina keluhuran peribadi sesama insan.

Pendidikan melalui teladan merupakan aspek penting yang perlu diterapkan dalam proses membimbing para pelajar kerana pendidikan melalui teladan juga dipandang baik sebagai suatu cara berkesan dalam membina akhlak dan menanam prinsip terpuji dalam jiwa pelajar, masyarakat dan negara. ${ }^{42}$

Nabi Muhammad s.a.w merupakan contoh teladan bagi seluruh umat Islam berperanan membimbing insan ke arah akhlak mulia sepertimana firman Allah SWT:

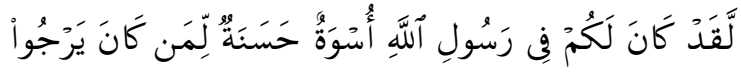

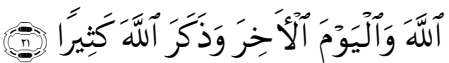

Terjemahan: Demi sesungguhnya, adalah bagi kamu pada diri Rasulullah itu contoh ikutan yang baik, iaitu bagi orang yang sentiasa mengharapkan (keredhaan) Allah dan (balasan baik) hari akhirat, serta ia pula menyebut dan mengingati Allah banyak-banyak (dalam masa susah dan senang).

42 Rashidi Abbas, Kemahiran Insaniah Meneroka Metodologi Rasulullah S.A.W (Pahang: Universiti Malaysia Pahang, 2008), 95. 
Masuriyati \& Che Zarrina, "Sistem Pendidikan Negara Abad ke-21," Afkār 16 (Januari-Jun 2015): 61-92

Al-Aḥzāb 33:21

Rasulullah s.a.w juga bersabda:

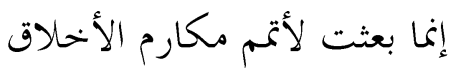

Terjemahan: Sesungguhnya aku dibangkitkan untuk menyempurnakan akhlak yang mulia. ${ }^{43}$

Kesempurnaan akhlak Rasulullah s.a.w pula telah disebutkan oleh Saiyidatina 'Aishah radhiallahu 'anha:

$$
\text { كان رسول اللّ خلقه القر آن }
$$

Terjemahan: Gambaran akhlak Rasulullah s.a.w ialah al-Quran. ${ }^{44}$

Dalam SPN21 proses pengajaran dan pembelajaran lebih berpusatkan pelajar sebagai satu pendekatan di mana pelajar perlu melibatkan diri secara aktif sepanjang proses pengajaran dan pembelajaran berjalan di samping guru hanya bertindak sebagai fasilitator atau pembimbing kepada pelajar. Melalui pendekatan pemusatan pelajar, proses pembinaan ilmu berlaku secara dua hala dengan lebih inovatif, kreatif, proaktif dan dinamik di samping menggalakkan gaya pembelajaran akses kendiri, konstruktif, pembelajaran aktif, koperatif, kolaboratif, inkuiri dan seumpamanya. ${ }^{45}$

Selain itu, penjanaan akhlak juga berlaku secara tidak langsung dalam proses pembinaan ilmu tersebut. Justeru,

43 Al-Bayhāqī, Kitāb Sunan al-Kubrā, Juz 10, Kitab al-Shahādah, Bāb Bayān Makārim al-Akhlāq wa Ma`ālih, No. Hadith 20174, J. 10. (Beirut: Dar al-Ma rifah, t.th.), 195.

44 Ibn Hanbal, Masnad al-Imām Ahmad, J. 9, Hadith no. 24774. (Beirut: Dār Ihyā' al-Turāth al-`Arabi, 1998).

45 Makmon, R., Mahamod, Z., Taib, N. I. M., \& Haron, R. A., Pengetahuan Teknologikal Pedagogikal Kandungan Kesusasteraan Melayu: Peranan Guru Sastera Dalam SPN 21 (Technological Pedagogical Content Knowledge in Malay Literature: The Roles of Malay Literature Teachers in SPN 21), Jurnal Pendidikan Bahasa Melayu; Malay Language Education (MyLEJ), 1 (2), (2011), 94. 
guru yang juga bertindak sebagai fasilitator dan juga pembimbing memainkan peranan penting untuk mengaplikasikan pendidikan melalui teladan meskipun pendekatan proses pengajaran dan pembelajaran lebih berpusatkan pelajar. Malah melalui pendekatan ini pendidikan melalui teladan mudah diterapkan di mana guru akan memberi tunjuk ajar dengan cara berhemah supaya pelajar faham dan dapat menghayati tunjuk ajar tersebut kemudian melakukannya sendiri berdasarkan arahan yang diberikan.

Guru yang mempunyai penyampaian yang baik dan berkesan dalam setiap pengajaran setentunya mempunyai sifat murabbi iaitu mereka mempunyai akal dan hati budi nurani yang ikhlas mengajar dan mencurahkan ilmu kepada para pelajar. Murabbi juga harus membimbing para pelajar ke arah kecemerlangan ilmu dan kemahiran beribadah kepada Allah agar peserta yang dididik tersebut berupaya memanfaatkan ilmunya dalam kehidupan sepanjang hayat. ${ }^{46}$

Jika sekiranya, pengajaran dan pembelajaran yang berjalan di dalam bilik darjah yang tidak selari dengan persekitaran luar yang nyata dan realiti akan menyebabkan timbulnya kekeliruan di kalangan pelajar. Ini disebabkan pengaruh persekitaran di luar bilik darjah lebih cepat berbanding dengan proses pembelajaran formal yang berjalan perlahan di dalam bilik darjah di mana pelajar lebih banyak belajar daripada apa yang dilihat berbanding dengan apa yang didengar. Sebagai contoh, guru mengajar tentang solat tetapi apabila pulang ke rumah, dia melihat ahli keluarganya tidak ada yang melakukan solat. ${ }^{47}$

Dengan kata lain, keberkesanan pendidikan melalui teladan adalah bergantung kepada sikap guru tersebut dan

46 Rashidi Abbas, Kemahiran Insaniah Meneroka Metodologi Rasulullah S.A.W (Pahang: Universiti Malaysia Pahang, 2008), 27.

47 Teks Perdana dalam Konvensyen Pendidikan Islam 2011 (Brunei: Pusat Persidangan Antarabangsa Berakas, 2011). 
untuk menjayakan pendidikan melalui teladan maka guru melaksanakan terlebih dahulu sebelum diajarkan kepada pelajar. Ini amat bertepatan dengan firman Allah SWT:

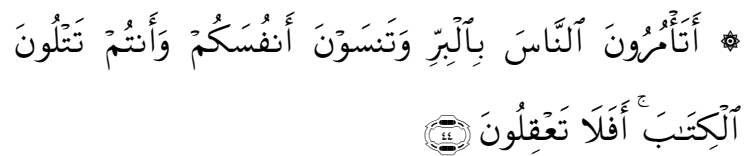

Terjemahan: Patutkah kamu menyuruh manusia supaya berbuat kebaikan sedang kamu lupa akan diri kamu sendiri; padahal kamu semua membaca Kitab Allah, tidakkah kamu berakal?

Al-Baqarah 2: 44

Allah berfirman di dalam surah al-Ṣāff:

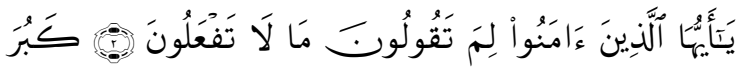

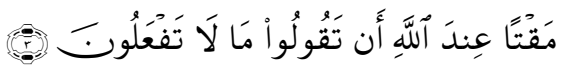

$$
\text { Al-Ṣāff (61): 2-3 }
$$

Justeru itu, penerapan pendidikan melalui teladan dan mewujudkan guru bersifat murabbi iaitu yang mendidik dan mengasuh amat penting di dalam proses pengajaran dan pembelajaran SPN21 agar dapat melahirkan generasi berilmu, beriman, beramal dan berakhlak sesuai dengan falsafah pendidikan negara Brunei Darussalam dan juga Wawasan 2035.

\section{Kesimpulan}

Sistem pendidikan yang solid dan mempunyai tujuan yang jelas amat penting dalam menjana generasi baru yang akan 
membangun negara sesuai dengan perkembangan abad ke21. Penyediaan kurikulum holistik dan dinamik yang menekankan kepentingan perkembangan dan kebahagiaan sejati individu dan juga kepentingan ilmu naqli dan 'aqli dalam proses pengajaran dan pembelajaran melalui pendekatan berpusatkan pelajar di samping kemahiran dan amalan pedagogi terbaik sesuai dengan perkembangan teknologi maklumat abad ke-21 akan mampu melahirkan insan soleh yang mempunyai sifat sentiasa ingat dan takut kepada Allah di setiap masa dan tempat sesuai dengan gagasan Negara Zikir untuk mencapai Wawasan 2035.

Keberkesanan SPN21 dalam pembentukan akhlak adalah bergantung kepada kejayaan guru menerapkan dan mengaplikasikan 'Pendidikan Melalui Teladan' iaitu guru melaksanakan terlebih dahulu sebelum diajarkan kepada pelajar di samping memiliki sifat murabbi iaitu perbuatan mengajar dan mendidik yang lahir dari hati nurani penuh ikhlas semoga mendapat keberkatan dari Allah jua. Generasi yang lahir hasil daripada SPN21 merupakan generasi harapan untuk terus melestari ketamadunan Negara Zikir Brunei Darussalam.

\section{Rujukan}

Abdul Aziz bin Juned. Negara Zikir, Kertas Perdana, Majlis Ilmu 2008 di Pusat Persidangan Antarabangsa, Berakas, 28-29 Julai 2008.

Abd Jalil Borham. Asas Pembangunan Modal Insan. Pahang: Universiti Malaysia Pahang, 2008.

Asar Abdul Karim. "Realiti Media Massa Masa Kini, Modal Insan Konsep, Aplikasi dan Isu-Isu Kontemporari”. Dalam Cabaran Pemerkasaan Tamadun Insan. Pahang: Universiti Malaysia Pahang, 2007.

Awg Asbol bin Haji Mail. "Sejarah Perkembangan Pendidikan di Brunei 1950-1985." Disertasi MA, Jabatan Sejarah, Fakulti Sastera dan Sains Sosial, Universiti Malaya, 1995/96. 
Kamus Dewan. Ed. ke-4. Kuala Lumpur: Dewan Bahasa dan Pustaka, 2007.

Haji Ali bin Haji Apong. "Teks Ucapan." Dalam Majlis Konvokesyen Kebangsaan Institut-Institut Pendidikan Teknik dan Vokasional ke-21. Brunei: Universiti Brunei Darussalam, 2014.

Hasan Langgulung. Pengenalan Tamadun Islam dalam Pendidikan. Kuala Lumpur: Dewan Bahasa dan Pustaka, 1986.

Hasan Langgulung. Asas Pendidikan Islam. Kuala Lumpur: Dewan Bahasa dan Pustaka, 1991.

Ibn Manzūr. Lisān al-`Arab. Beirut: Dar al-Sadir dan Dar Beirut, 1955.

Makmon, R., Mahamod, Z., Taib, N. I. M., dan Haron, R. A. Pengetahuan Teknologikal Pedagogikal Kandungan Kesusasteraan Melayu: Peranan Guru Sastera dalam SPN 21, Jurnal Pendidikan Bahasa Melayu, (2011).

Malaysia, P. I. P. Pengaruh Media Massa Terhadap Penampilan Akhlak. The Online Journal of Islamic Education, (2013).

Mohammad Huzaiman bin Haji Kassim. "Adakah Spn21 Itu Mendukung Visi dan Misi Jabatan Pengajian Islam?" Makalah, Fakulti Usuluddin, Kolej Universiti Perguruan Ugama Seri Begawan, 2009.

Pelita Brunei. Jabatan Penerangan, Jabatan Perdana Menteri, Negara Brunei Darussalam.

Pg Dr Haji Mohammad Pg Haji Abd Rahman. Islam di Brunei Darussalam. Brunei: Dewan Bahasa dan Pustaka, 2001.

Pg Dr Haji Mohammad Pg Haji Abd Rahman. Belia dan Pendidikan Islam di Brunei Darussalam. Brunei: Pusat Da'wah Islamiah, 2011.

Pg Dr Haji Mohammad Pg Haji Abd Rahman. "Perkembangan Ilmu Islam di Brunei: Peralihan Dari Sistem Balai ke Sistem Persekolahan Moden (1931- 
1956)." Makalah, Seminar Bahan Rujukan Islam Nusantara, Jabatan Mufti, 20-23 Ogos 2001.

Pg Dr Haji Mohammad Pg Haji Abd Rahman dan Mahayudin Yahaya. Tamadun Melayu Islam di Alam Melayu: Kes Brunei Darussalam. Brunei: Pusat Da'wah Islamiah, 2011.

Rashidi Abbas. Kemahiran Insaniah Meneroka Metodologi Rasulullah S.A.W. Pahang: Universiti Malaysia Pahang, 2008.

Sahari Akim. Keluaran Khas Sempena Sambutan Hari Kebangsaan ke-24, Pelita Brunei, 2008.

Sistem Pendidikan Negara Abad Ke-21 SPN21. Kementerian Pendidikan Negara Brunei Darussalam, 2008.

Syed Muhammad Al-Naquib Al-Attas. Tujuan Dan Objektif Pendidikan Islam, terj. Samsudin Jaapar. Kuala Lumpur: Dewan Bahasa dan Pustaka, 1992.

Tassim Abu Bakar. Pendidikan dari Balai di Kampong Ayer ke Sekolah Moden di Darat, 1906-1941: Kajian Sejarah Pendidikan di Negara Brunei Darussalam, Jurnal Kajian Sejarah dan Pendidikan Sejarah, (2013).

Teuku Iskandar. Kamus Dewan. Kuala Lumpur: Dewan Bahasa dan Pustaka, 1970.

Wan Mohd Nor Wan Daud. Falsafah dan Amalan Pendidikan Islam Syed M.Naquib Al-Attas Satu Huraian Konsep Asli Islamisasi. Kuala Lumpur: Universiti Malaya, 2005.

Yahya Ibrahim. Tugas Ulama dalam Usaha Pembangunan Umat. Brunei: Pusat Da'wah Islamiah, 2002.

Laman sesawang International Telecommunication Union http://www.internetworldstats.com. 
Masuriyati \& Che Zarrina, "Sistem Pendidikan Negara Abad ke-21," Afkār 16 (Januari-Jun 2015): 61-92 